\title{
Th_P10_02
}

\section{Comprehensive Characterization of Arab-D Reservoir Equivalent Outcrop Well Cores from Upper Jubaila Formation, Saudi Arabia}

\author{
V. Chandra ${ }^{1}$, A.I. Ramdani ${ }^{1}$, T. Finkbeiner ${ }^{1 *}$, B. Yalcin ${ }^{1}$, P. Khanna ${ }^{1}$, A. Petrovic ${ }^{1}$, V. \\ Vahrenkamp ${ }^{1}$
}

${ }^{1}$ KAUST

\section{Summary}

The work presented here is part of a multidisciplinary research project that aims to develop high fidelity geomodels, of Jurassic hydrocarbon reservoirs in Saudi Arabia, suitable for IOR/EOR reservoir simulation studies through careful integration of outcrop and subsurface data. An integrated petrophysical and rock mechanics characterization of 35 meters outcrop well cores from the Upper Jubaila section was performed, which provides an analogue to the lower Arab-D reservoir unit. Preliminary petrographic analysis indicated a strong diagenetic overprint of the core by telogenetic products. The diagenetic factors as well as the rock mechanical and petrophysical properties are the main controls on the fine-scale mechanical stratigraphy. The findings from this study will contribute to the development of high fidelity geomodels of Jurassic hydrocarbon reservoirs in Saudi Arabia, suitable for IOR/EOR reservoir simulation studies. 


\section{Introduction}

The Arab-D reservoir in Saudi Arabia is the world's most prolific hydrocarbon reservoir lithostratigraphically hosted by the Late Jurassic Arab-D and Upper Jubaila Formations (Lindsay et al. 2006). In order to maintain production levelsin the future and to access remaining recoverable oil reserves ultimate recovery is increased through IOR/EOR techniques. Because the lower reservoir sections - namely the Upper Jubaila - are interlayered and tight water fingering and uneven flood fronts are common the risk for by-passed oil is high. To increase ultimate recovery key controlling factors such as reservoir architecture, lateral and vertical extent of lithofacies, rock and geo-mechanical settings, and fracture network distribution and connectivity need to be better understood. In this context, outcrop analogues allow more extensive and laterally continuous measurements leading to high resolution 3D data, which when combined and calibrated with subsurface data can significantly reduce uncertainties and improve our understanding of the reservoir complexity - in particular in the inter-well volumes. The work presented here is part of a multidisciplinary research project that aims to develop high fidelity geomodels of Jurassic hydrocarbon reservoirs in Saudi Arabia, suitable for IOR/EOR reservoir simulation studies. The current study is focused on an outcrop section from the Upper Jubaila Formation equivalent to the lower Arab-D reservoir. We present a comprehensive petrophysical and rock mechanics characterization study of near surface core drilled in close proximity to the outcrop.

\section{Geological setting}

The Jubaila Formation is early Kimmeridgian in age and informally divided into J1 and J2 (Figure 1a). It conformably overlies the Hanifa Formation and is conformably overlain by Arab D (Manivit et al. 1985, Al-Mojel, 2017). Unit J1 is an interbedded limestone with bioclastic and intraclastic grainstone beds whereas unit $\mathrm{J} 2$ is characterized by reworked bioclastic cross-bedded grainstone, interbedded bioturbated mudstone and intraclastic grainstone, and stromatoporoid bistromal beds (Al-Mojel 2017).

\section{A}

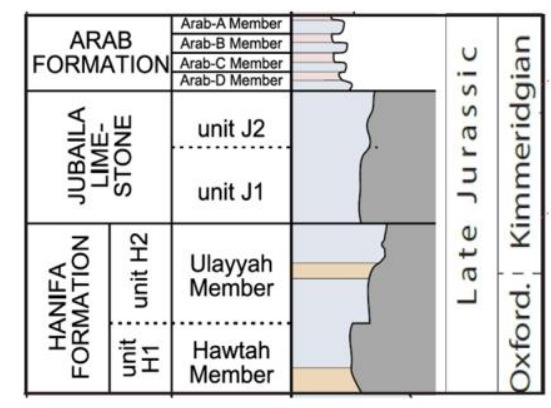

C

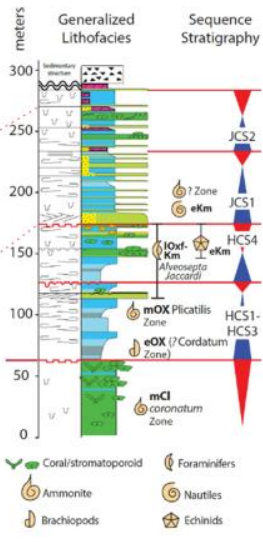

$46^{\circ} 36^{\circ} 0^{\circ} \mathrm{E}$

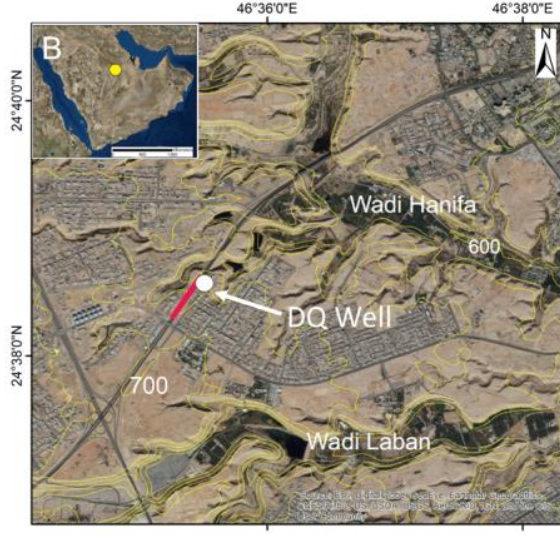

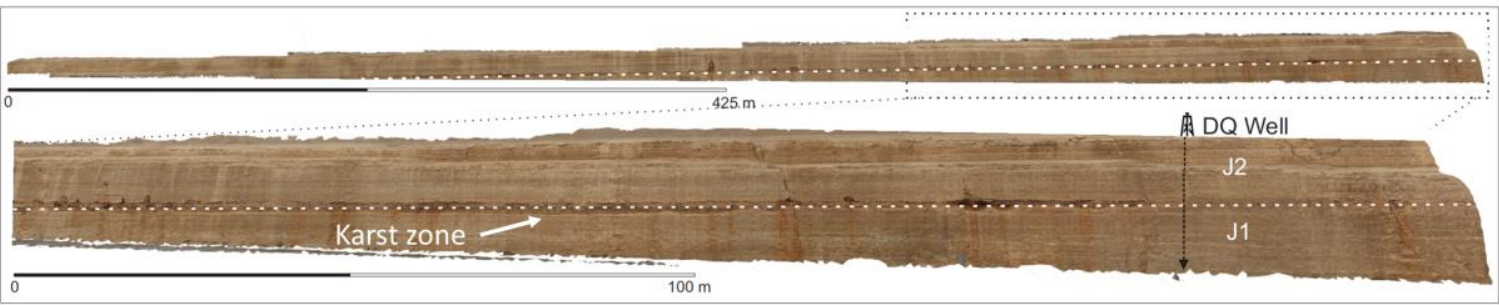

Figure 1 (A) Lithostratigraphy and chronostratigraphy of Jurassic Arabian outcrops of the Late Jurassic Hanifa and Jubaila formations (modified from Al-Mojel 2017). (B) Location of the DQ well (this study) in southwestern Riyadh (The yellow dot in the inset is Riyadh's approximate location on the Arabian peninsula). Locations of Wadi Laban and Wadi Hanifa are labeled. The red line depicts the road cut shown in $(C)$. The cliff is $850 \mathrm{~m}$ long with the projected location of the $D Q$ well (this study). A continuous karstified unit divided exposed Jubaila outcrop into J1 and J2.

The depositional environment has been a topic of debate for several decades. Some propose shallow lagoonal depositional settings whilst others postulate deep basinal depositional settings (Mitchell et al, 1988; Meyer and Price 1993; Handford et al., 2002; Lindsay et al., al., 2006; Al-Mojel 2017). Recent 
chronostratigraphic correlation of the Jubaila formation by Al-Mojel (2017) describes the Jubaila Arab-D system as two composite sequences with the lithostratigraphic boundary between Jubaila and Arab-D to be located within the second composite sequence.

\section{Data set and methodology}

The study area is located in Wadi Laban, on the western side of Riyadh, where the Upper Jubaila Formation is exposed on the Mecca-Riyadh highway along an $800 \mathrm{~m}$ road cut section (Figure 1b, c). The cores pieces used for this study were retrieved from a 35 meter deep and continuously cored well, the DQ Well, drilled $20 \mathrm{~m}$ away from the face of the road cut (Figure 1b). Following medical-CT imaging and spectral gamma ray measurement, scratch testing was performed on the whole core pieces to obtain continuous uniaxial compressive strength (UCS) profiles and ultrasonic acoustic measurements. The whole core pieces were then slabbed and 103 core plugs were obtained (sub-parallel to bedding) using a regular sampling interval of approximately 1 foot. The core plugs were then trimmed to be 1 inch in diameter and 2 inch in length. The trim-ends were used further for petrographic thin sections and samples for x-ray diffraction (XRD) analysis, mercury injection porosimetry (MIP) and scanning electron microscope (SEM) imagery. Helium porosity and air permeability measurements were acquired for all the trimmed core plugs. A detailed core description was performed on the slabbed cores to obtain the depositional facies log versus depth.

\section{DQ well core characterization}

The predominant lithofacies in the studied DQ Well interval as observed from core description and preliminary petrographic analysis are bioturbated mudstones intercalated by packstones and grain dominated rudstone and floatstone. As expected, petrographic analysis indicated a strong diagenetic overprint of the core by telogenetic products. Compared to the paragenetic sequence described for the Arab-D reservoir (Rosales et al., 2018), the investigated carbonate rock appears to be altered by dedolimitization and intensive neomorphisim during the uplift of the rock strata. Figure 2a presents the correlation panel of the petrophysical and rock mechanics data versus depth. The well section has been subdivided into two intervals, $\mathrm{J} 1$ and $\mathrm{J} 2$, based on the presence of a karst zone that is found to be laterally extensive across the Wadi Laban / Wadi Hanifa area (Figure 1c, 2b).
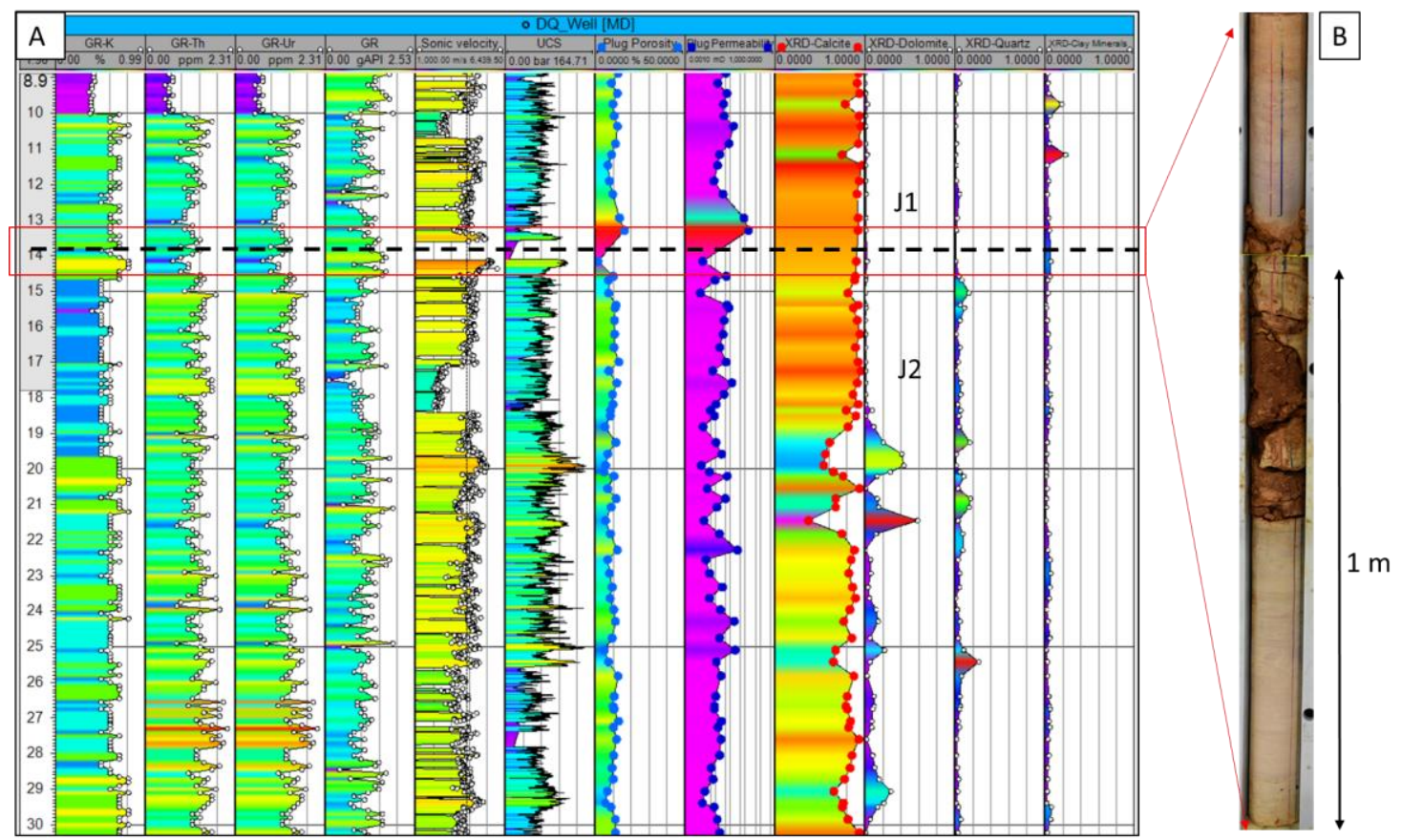

Figure 2 (A) Correlation panel of $D Q$ Well petrophysical and rock mechanical log data. From left to right: measured depth $(\mathrm{m}), G R-K$, Th and $U$, total $G R$, sonic velocity $[\mathrm{m} / \mathrm{s}]$, rock strength [bar], plug porosity, plug permeability $[\mathrm{mD}], \mathrm{XRD}$ profiles of calcite, dolomite, quartz and clay minerals. (B) Core section heavily altered due to karstification. 
In contrast to the $\mathrm{J} 1$ interval in the upper portion of the core, the lower $\mathrm{J} 2$ section is dominated by dolomite and quartz rich facies as observed from powder XRD logs and corroborated by thin section and SEM analyses (Figure 3a, b). Whole core medical CT data further confirms the extensive distribution of these facies in this interval at the meter scale. Figure $3 \mathrm{c}$ shows the cross-plot of core plug porosity and permeability coloured by continuous rock strength data obtained from scratch testing. The mean porosity value is $15 \%$ and the permeability ranges from $0.01-16 \mathrm{mD}$, and UCS values from the scratch test generally increase with decreasing porosity.

The UCS histogram in Figure 3d shows a Gaussian distribution with a mean value of 68.3 MPa and a standard deviation of 19.5 MPa. Similar trends are observed for the three predominant facies. To estimate a sub-surface based strength profile we also calculated UCS values using the formulas derived by Ameen et al. (2009) and DQ Well core plug porosity data. The results indicate that on average compressive rock strength from the scratched core for mudstones is within 5\% (or $4 \mathrm{MPa}$ ), packstones within $19 \%$ (or 12MPa), and rudstones within $22 \mathrm{MPa}$ (or 32\%) of the sub-surface derived porosityUCS algorithms. In other words, the greater the current core porosity the larger the difference in strength. Furthermore, it also implies that even though current grain- or rudstones have the highest porosity values, compressive strength is not influenced as much as predicted by the sub-surface correlation; the rock frame provides the apparent high strength measured by the scratch test. We can conclude further that from a rock mechanical perspective mudstones with their original low porosity and permeability values were probably less affected by a diagenetic overprint compared to packstones and rudstones. In particular the latter facies appears to have experienced a marked strengthening effect.
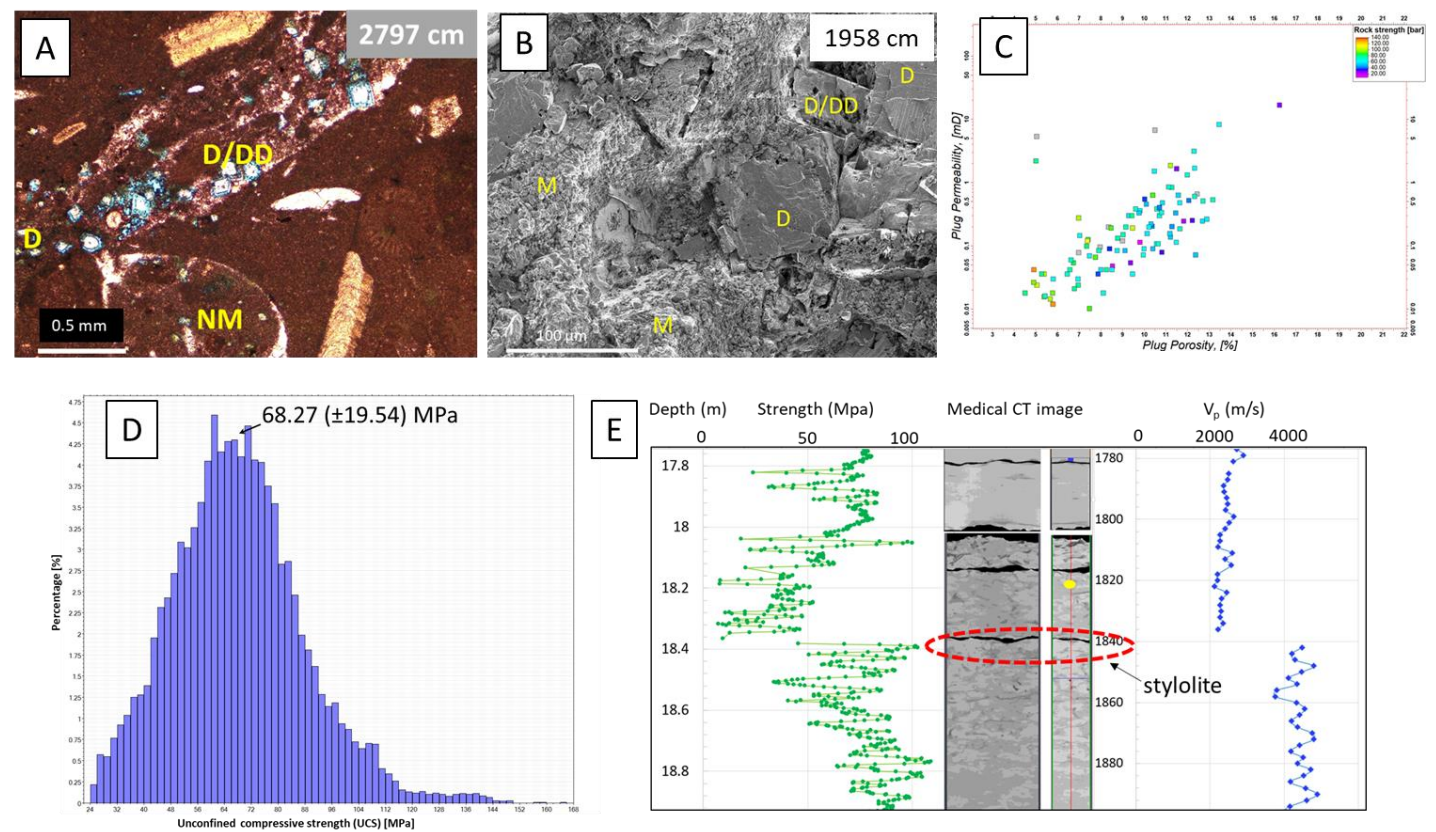

Figure $3(A)$ Thin-section petrograph showing the presence of dolomite $(D)$, dedolomitization $(D D)$ and neomorphic microsparite (NM). (B) SEM image illustrating the presence of fused micrite (M) and dolomite. (C) Porosity-permeability cross plot showing higher strength vales at lower porosity. (D) Histogram of UCS from scratch test. (E) Marked localized change in rock strength and sonic Vp above and below a stylolite, possibly due to the rapid increase in high density facies as seen in the CT data.

Within the DQ Well core interval, the trends in the UCS and sonic log data within the J1 and J2 intervals reveal a more detailed mechanical layering than does the histogram and cumulative statistical analysessuggest. In particular, the depth interval from approximately $17.0 \mathrm{~m}$ to $19.6 \mathrm{~m}$ shows unexpected variability above and below a stylolite (Figure 3e). This dramatic, fine-scale change in strength and rock velocity can be explained by the abundance of high density rock facies as observed in the whole core medical CT scans. Preliminary analyses of thin-section, XRD and SEM data indicate that the high density of these facies could be attributed to the compounded effect of fused micrite, dolomite and 
telogenetic re-crystallization manifested as neomorphic microsparite, especially below $18 \mathrm{~m}$. A thorough investigation of the petrographic and SEM data will be conducted to confirm these findings.

\section{Conclusions}

An integrated petrophysical and rock mechanics characterization of 35 meters of outcrop well cores from Upper Jubaila section analogous to lower Arab-D reservoir unit was performed. Preliminary petrographic analysis indicated a strong diagenetic overprint of the core by telogenetic products. At the meter scale the UCS data followed a Gaussian distribution irrespective of the facies types and UCS values generally increased with decrease in porosity. Strength profiles of each major facies type were compared with those estimated using the formulas derived by Ameen et al. (2009) using plug porosity. The strength profile of grainstone- rudstone facies showed the highest deviation from the corresponding subsurface estimates. At the cm-scale marked differences are observed in the rock strength and velocity trends between the upper (J1) and lower (J2) sections of the well interval, indicating strong correlation between the occurrence of stylolites and fine-scale mechanical stratigraphy. The findings from this study will contribute to the development of high fidelity geomodels of Jurassic hydrocarbon reservoirs in Saudi Arabia, suitable for IOR/EOR reservoir simulation studies.

\section{References}

Al-Mojel, A. 2017. Sedimentology and Sequence Stratigraphy of the Jurassic, Jabal Tuwaiq, Central Saudi Arabia. L’Université Bordeaux Montaigne, Ph.D. Thesis.

Ameen, M. S., Smart, B. G. D., Somerville, J. M., Hammilton, S., \& Naji, N. A. (2009). Predicting rock mechanical properties of carbonates from wireline logs (A case study: Arab-D reservoir, Ghawar field, Saudi Arabia). Marine and Petroleum Geology, 26(4), 430-444. https://doi.org/10.1016/j.marpetgeo.2009.01.017

Handford, C.R., Cantrell, D.L., Keith, T.H., 2002, Regional facies relationships and sequence stratigraphy of a super-giant reservoir (Arab-DMember), SaudiArabia: Society of Economic Paleontologists Gulf Coast Section Research Conference Programand Abstracts 22, 539-563.

Lindsay, R.F., Cantrell, D.L., Hughes, G.W, Keith, T.H., Mueller III, H.W., Russell, D., 2006. Ghawar Arab-D reservoir: Widespread porosity inshoaling-upward carbonate cycles, Saudi Arabia: AAPG Memoir 88, 97- 138.

Manivit J, Le Nindre, Y.M., Vaslet D. (1990) Le Jurassique d'Arabie Centrale. In Histoire Gologique de la Bordure Occidentale de la Plate-forme Arabe. Volume 4. Document du BRGM nº194.

Meyer, F.O., Price, R.C., 1993. A new Arab-D depositional model, Ghawar Field, Saudi Arabia. In: Paper Presented at the Middle East Oil Show, Bahrain.

Mitchell, J.C., Lehmann, P.J., Cantrell, D.L., Al-Jallal, I.A., Al-Thagafy, M.A.R., 1988. Lithofacies, diagenesis and depositional sequence: Arab-D Member, Ghawar Field, Saudi Arabia. SEPM Core Workshop 12, 459- 514.

Rosales, I., Pomar, L., Al-Awwad, S.F., 2018. Microfacies, diagenesis and oil emplacement of the Upper Jurassic Arab-D carbonate reservoir in an oil field in central Saudi Arabia (Khurais Complex). Marine and Petroleum Geology, 96, 551-576. 